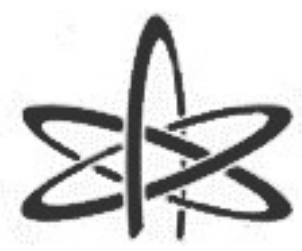

BJRS
BRAZILIAN JOURNAL

$\mathrm{OF}$

RADIATION SCIENCES

08-03B (2021) 01-13

\title{
CHF prediction in rod bundles using round tube data
}

\author{
Souza $^{a}$ W. F., Veloso ${ }^{a}$ M. A. F., Pereira ${ }^{a}$ C., $\operatorname{Costa}^{a}$ A. L. \\ ${ }^{a}$ Universidade Federal de Minas Gerais/Departamento de Engenharia Nuclear \\ 31270-901 Av. Antônio Carlos 6627, Belo Horizonte, MG, Brazil \\ mdora@nuclear.ufmg.br
}

\begin{abstract}
The present work concerns the use of 1995 CHF table for uniformly heated round tubes, developed jointly by Canadian and Russian researchers, for the prediction of critical heat flux in rod bundles geometries. Comparisons between measured and calculated critical heat fluxes indicate that this table can be applied to rod bundles provided that a suitable correction factor is employed. The tolerance limits associated with the departure from nucleate boiling ratio (DNBR) are evaluated by using statistical analysis.
\end{abstract}

Keywords: critical heat flux, subchannel code, STHIP. 


\section{INTRODUCTION}

The present work concerns with the assessment of critical heat fluxes (CHF) in rod bundles geometries. CHF is an important parameter to be predicted when considering the safety limits of nuclear reactors, steam generators and other thermal units. When CHF occurs, the heat transfer capability decreases dramatically and the corresponding wall temperature increases rapidly that it can even melt the heat transfer surface. The power generated is often limited by the CHF value. The pressurized water nuclear reactors must be designed with sufficient thermal power margin for the specifically acceptable fuel design limits to ensure that they are operated safely within the limiting conditions for operation.

Many different models and correlations for the prediction of CHF exist in the literature and an enormous amount of experimental data are available nowadays. Most of the studies carried out on CHF have been reviewed in various publications by Katto [1], Tong [2], Todreas and Kazimi [3], Collier and Thome [4] and Tong and Weisman [5].

In general, CHF correlations are applicable to specific geometries and cover specific ranges of parameters. They cannot be extrapolated to conditions far beyond the ranges of their data bases. To overcome this difficulty, Doroschuk et al. [6,7] proposed the first standard table for calculating CHF in uniformly heated round tubes cooled by boiling water. The model developed by Doroschuk et al. is based on the hypothesis that the critical heat flux is solely a function of flow parameters at the point where CHF occurs. Then, it is assumed that the history of the flow has no effect on the critical heat flux.

Since the publication of Doroschuk et al., development works of CHF tables have been continued in Russia and Canada. In 1986, Groeneveld, Cheng and Doan [8] published the 1986 AECLUO CHF table. This table, based on about 15000 tube data, covers wider ranges of flow conditions. Kirillov et al. [9] improved the table of Doroschuk et al. by using a data base with 7620 data points. The 1995 CHF table [10] was developed jointly by Atomic Energy of Canada Ltd. (AECL, Chalk River, Canada) and Institute of Physics and Power Engineering (IPPE, Obninsk, Russia) and was derived from a combined AECL-IPPE world data bank consisting of about 23000 data points. It covers the following ranges of parameters: pressure, 0.1 to $20.0 \mathrm{MPa}$; mass flux, 0 to $8000 \mathrm{~kg} / \mathrm{m}^{2} \mathrm{~s}$; quality, 0.5 to 1.0 ; diameter, 0.003 to $0.04 \mathrm{~m}$; and length to diameter ratio, 80 to 2485 . 
Considering that the critical heat flux is determined by the flow conditions where the phenomenon occurs, the CHF tables, although derived for upward flow in a uniformly heated 8-mm tube, can also in principle be extended to rod bundles. Correction factors to the tables taking into account the effects of grid spacers, cold wall, nonuniform heat flux on CHF might be necessary when using them for rod bundles. Rod bundle correction factors applicable to the 1986 AECL-UO CHF table are reported by Groeneveld et al. [8,11].

In this paper, the 1995 CHF table is compared with measurements of critical heat flux taken from electrically heated 25-rods bundles arranged in 5x5 square arrays. The rod bundle test section geometries and the ranges of operating parameters are representative of those found in the cores of pressurized water reactors (PWR). The predicted local subchannel conditions are substituted into the proposed CHF model to obtain a distribution of the departure from nucleate boiling ratios (DNBR) as a function of local steam quality; and the upper one-sided tolerance limit for the DNBR is estimated by applying statistical methods to the DNBR data.

For the continuous monitoring of the minimum DNBR, empirical correlations were developed based on experimental data, obtained in sections of tests that simulate the geometric and operational conditions of the fuel elements. Usually, the analysis of the experimental CHF data in rod bundle is done through computational programs, which calculate the local conditions of the flow, using the technique known as subchannel analysis. Here the subchannel code STHIRP-1 [12] was used. It is a modified version of the COBRA-IIIC [13], developed in the Department of Nuclear Engineering/UFMG. The subchannel programs calculate the local conditions of the fluid and provide, based on empirical correlations or alternatively using tables as done in this work, the value of the local heat flux that, under those conditions, critical heat flux occurs. The use of these programs is complex, requiring a large set of input data, with results dependent on the specification of input data, such as local pressure loss coefficients, friction coefficients, mixing factor between the subchannels, among others.

This process accumulates uncertainties of various natures. Among the most important are those associated to the development of the adopted empirical correlation, the several experimental parameters of the test sections, as well as the theoretical and numerical models associated with the computational code. In addition to these limitations, it is also worth mentioning the high cost of the critical heat flux experiments, which prevents the execution of runs involving different geometric and oper- 
ational conditions of the test sections, making it difficult to accurate analysis of the effect of several parameters.

\section{MATERIALS AND METHODS}

A total of $2542 \mathrm{CHF}$ data points from 34 test sections with 25 rods in a $5 \times 5$ square array were selected for assessment in this study. These CHF data were taken from data base compiled by Figuetti and Reddy [14] at Columbia University. The sources of the data are Babcock and Wilcox Co. (BW), Combustion Engineering In. (CE), Exxon Nuclear Co. (EX), Idaho National Engineering Laboratories (IN), and Westinghouse Electric Co. (WE).

Figure 1 illustrates a cross sectional view of a typical $5 \times 5$ rod bundle. Stainless steel or inconel tubes electrically heated are usually employed to simulate nuclear fuel rods. Control rod guide thimbles are simulated by unheated tubes.

Radial power is obtained by using heater tubes of the same outer diameter and different wall thicknesses. The rods spacing is maintained by different types of mixing vane grids and simple support grids. The rod bundle is contained in a vertical square tube lined with ceramic walls for electrical insulation. Water flows upward inside the tube and outside the rods, removing the heat generated within the heaters. All test sections have uniform axial heat flux profiles.

Thermocouples mounted inside the heater rods near the end of the active length detect the change in the surface temperature associated with CHF. The heater rods are filled with hollow ceramic cylinders which prevent deformation of the wall tubing and electrically insulate the CHF thermocouple sheaths.

Normally, CHF experiments are conducted in the same way. For each CHF run, the test parameters (pressure, inlet temperature and flow rate) are preset to the desired values and electric power to the bundle is then gradually increased until a fast increase in surface temperature is detected by one or more of the CHF thermocouples. When the indication is assessed to be sufficient to establish the occurrence of $\mathrm{CHF}$, the test section power is immediately reduced by the operator or automatically turned-off. Voltage, current, inlet temperature, inlet flow rate, outlet pressure, identification num- 
bers of rods and thermocouples indicating CHF are continuously recorded. The set of measurements taken immediately before the power reduction constitutes the recorded CHF conditions.

Figure 1: Cross-sectional view of a $5 \times 5$ rod bundle

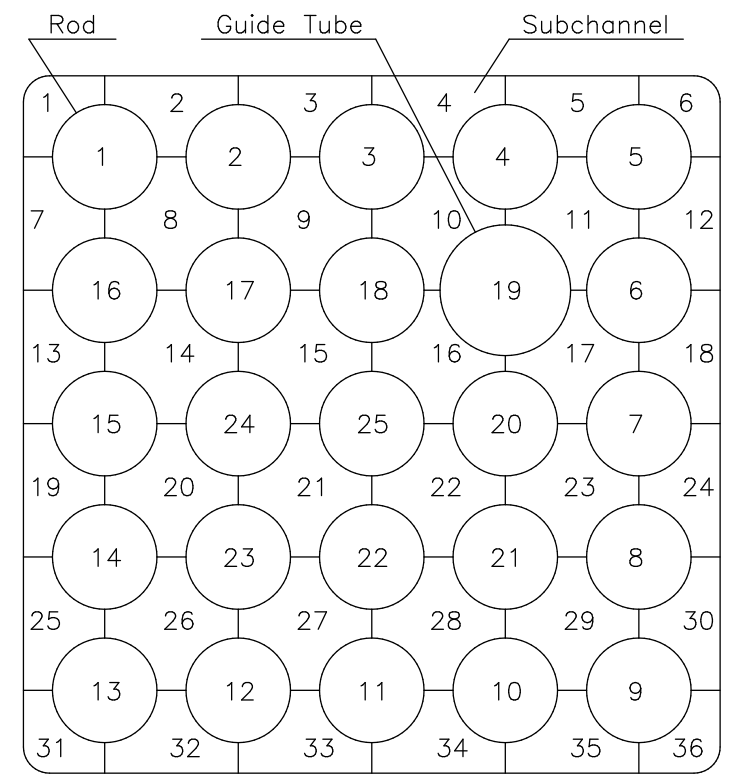

Source: Author

The database used in this work covers the following parameter ranges: pressure, 1.3 to $17 \mathrm{MPa}$; inlet temperature, 95 to $340{ }^{\circ} \mathrm{C}$; average mass flux, 220 to $6050 \mathrm{~kg} / \mathrm{m}^{2} \mathrm{~s}$; average heat flux, 220 to $3930 \mathrm{~kW} / \mathrm{m}^{2}$.

Subchannel mass flux and steam quality at the CHF location for each critical heat flux run were calculated with the STHIRP-1 subchannel code from values of pressure, inlet temperature, bundle average mass flux, and bundle average heat flux.

Calculations with the STHIRP-1 subchannel code were carried out by using the input parameters and correlations summarized in Table 1. Parameters given in Table 1 have the same definitions as those ones used in the COBRA-IIIC code. The extent of turbulent mixing among subchannels was determined using a turbulent mixing coefficient $(\beta)$ of 0.050 [15]. It should be emphasized that the CHF subchannel was assumed to be that subchannel adjacent to the CHF rod presenting in calculation the highest exit steam quality. 
Table 1: Input parameters and correlations for STHIRP-1

\begin{tabular}{lc}
\hline Number of axial levels & 41 \\
Convergence tolerance for axial flow & 0.001 \\
Convergence tolerance for crossflow & 0.01 \\
Crossflow resistance factor, $\mathrm{K}_{0}$ & 0.5 \\
Transverse momentum parameter & 0.5 \\
Turbulent momentum factor, $\mathrm{f}_{\mathrm{t}}$ & 1.0 \\
Turbulent mixing coefficient & 0.05 \\
Friction factor correlation & Blasius [4] \\
Subcooled void correlation & Levy [16] \\
Bulk void correlation & Smith [17] \\
Two-phase friction multiplier correlation & Reddy et al.[18]
\end{tabular}

When the calculated subchannel conditions at the location of critical heat flux for a particular run are substituted into a CHF correlation, a predicted CHF is produced. The ratio of the predicted CHF to the local CHF is defined as the Departure from Nucleate Boiling Ratio (DNBR). Since the local CHF for each experiment is just the measured CHF, this definition results in

$$
D N B R=\frac{q_{\text {crit,predicted }}^{\prime \prime}}{q_{\text {crit,measured }}^{\prime \prime}}
$$

where q" crit denotes the critical heat flux.

The DNBR values should be one at all CHF test conditions if experimental errors were zero, if the flow parameters at the CHF location were perfectly determined by a subchannel code, and if the critical heat fluxes were exactly predicted by the CHF correlation. In general, these conditions do not happen and the DNBR data are found to produce a probability distribution. If the distribution is normal, then a minimum DNBR (MDNBR) thermal design limit may be determined such that CHF will not occurs at $95 \%$ probability with $95 \%$ confidence level. 
When a sample $\mathrm{DNBR}_{1}, \mathrm{DNBR}_{2}, \ldots, \mathrm{DNBR}_{\mathrm{n}}$ is taken, the mean value is given by

$$
\overline{\mathrm{DNBR}}=\frac{1}{\mathrm{n}} \sum_{\mathrm{i}=1}^{\mathrm{n}} \mathrm{DNBR}_{\mathrm{i}}
$$

and the standard deviation may be evaluated from

$$
\mathrm{S}=\left\{\frac{1}{\mathrm{n}-1}\left[\sum_{\mathrm{i}=1}^{\mathrm{n}}\left(\mathrm{DNBR}_{\mathrm{i}}-\overline{\mathrm{DNBR}}\right)^{2}\right]\right\}^{1 / 2}
$$

where $\mathrm{n}$ is the total number of data.

The average error and the root-mean-square error are defined as

$$
\begin{aligned}
& \varepsilon_{\text {avg }}=\frac{1}{\mathrm{n}} \sum_{\mathrm{i}=1}^{\mathrm{n}} \varepsilon_{\mathrm{i}} \\
& \varepsilon_{\mathrm{rms}}=\left[\frac{1}{\mathrm{n}} \sum_{\mathrm{i}=1}^{\mathrm{n}} \varepsilon_{\mathrm{i}}^{2}\right]^{1 / 2}
\end{aligned}
$$

where

$$
\varepsilon_{\mathrm{i}}=\left(\frac{\mathrm{q}_{\text {crit,predicted }}^{\prime \prime}-\mathrm{q}_{\text {crit,measured }}^{\prime \prime}}{\mathrm{q}_{\text {crit,measured }}^{\prime \prime}}\right)_{\mathrm{i}}=\mathrm{DNBR}_{\mathrm{i}}-1
$$

A typical Pressurized Water Reactor (PWR) design criterion is that CHF will not occur in the core at a $95 \%$ probability with a $95 \%$ confidence level. In order to meet this criterion, a limiting value of DNBR is determined by applying statistical methods to random samples of DNBR data taken from tests simulating reactor conditions. The minimum design value for the DNBR for PWR is 1.30. Needless to say, the establishment of a minimum DNBR provides a major limitation on the design of water-cooled reactors. The maximum heat flux anywhere in the core is limited by the DNBR.

For a normal random variable DNBR with unknown mean $\mu$ and standard deviation $\sigma$, the upper one-sided tolerance limit for the DNBR is given by Eq.7.

$$
\mathrm{MDNBR}=\overline{\mathrm{DNBR}}+\mathrm{K} \cdot \mathrm{S}
$$


where $\overline{\mathrm{DNBR}}$ is an estimate of $\mu$ and $\mathrm{S}$ is an estimate of $\sigma$. Values of $\mathrm{K}$ such that the probability is $\gamma$ that at least a proportion $\mathrm{p}$ of a normal distribution is below the minimum DNBR (MDNBR) may be obtained from tables given in textbooks of statistics.

\section{RESULTS AND DISCUSSION}

The ratios of predicted to measured critical heat fluxes obtained by using the $1995 \mathrm{CHF}$ table are plotted in Fig. 2 as a function of local steam quality. The points on the line DNBR $=1.0$ indicates that the predictions match the measurements. The points above this line mean that the proposed model overestimates the predicted critical heat fluxes. Desirable predictions are indicated by the points falling below the line DNBR $=1.0$.

Figure 2: Ratio of predicted CHF to measured CHF as a function of local steam quality.

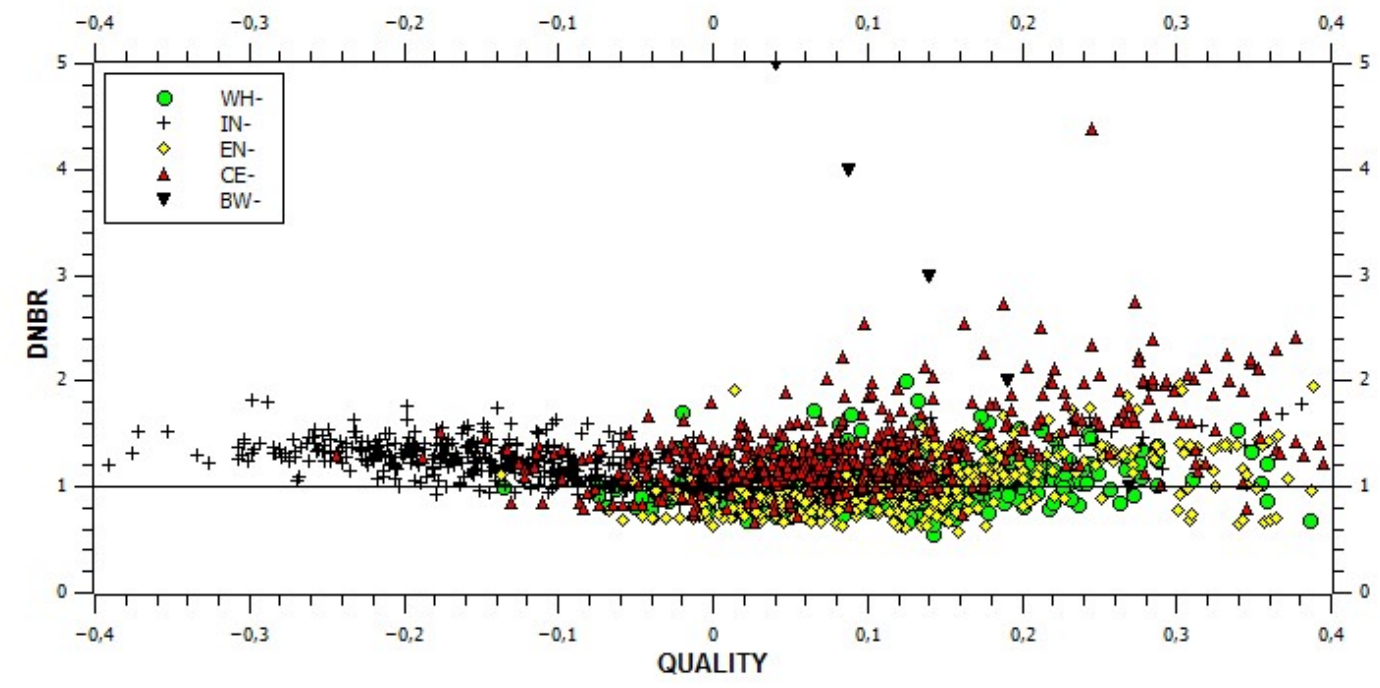

Source: Author

It can be inferred from Fig. 2 that the DNBR data points are distributed around DNBR $=1.0$ and that most of the data falls within the range $0.7 \leq \mathrm{DNBR} \leq 1.5$. The mean value and standard deviation associated with the set DNBR data points are 1.153 and 0.322 , respectively. Table 2 summarizes the mean value and the standard deviation associated with DNBR data points from each technical 
institution.

Table 2: Mean values and standard deviations by institution

\begin{tabular}{lcc}
\hline \multicolumn{1}{c}{ Institution } & Mean Value & Standard Deviation \\
\hline Babcock and Wilcox Co. & 1.011 & 0.252 \\
Combustion Engineering In. & 1.397 & 0.418 \\
Exxon Nuclear Co. & 1.075 & 0.299 \\
Idaho National Engineering Lab. & 1.195 & 0.194 \\
Westinghouse Electric Co. & 1.013 & 0.209 \\
\hline
\end{tabular}

The 1995 CHF table predicts close to $68 \%$ of the data within the $\pm 15 \%$ error range. This is shown in Fig. 3, where the error histogram is plotted using 10\% error intervals. Gauss's curve shows that the results present a normal distribution.

Figure 3: Histogram of the DNBR data points.

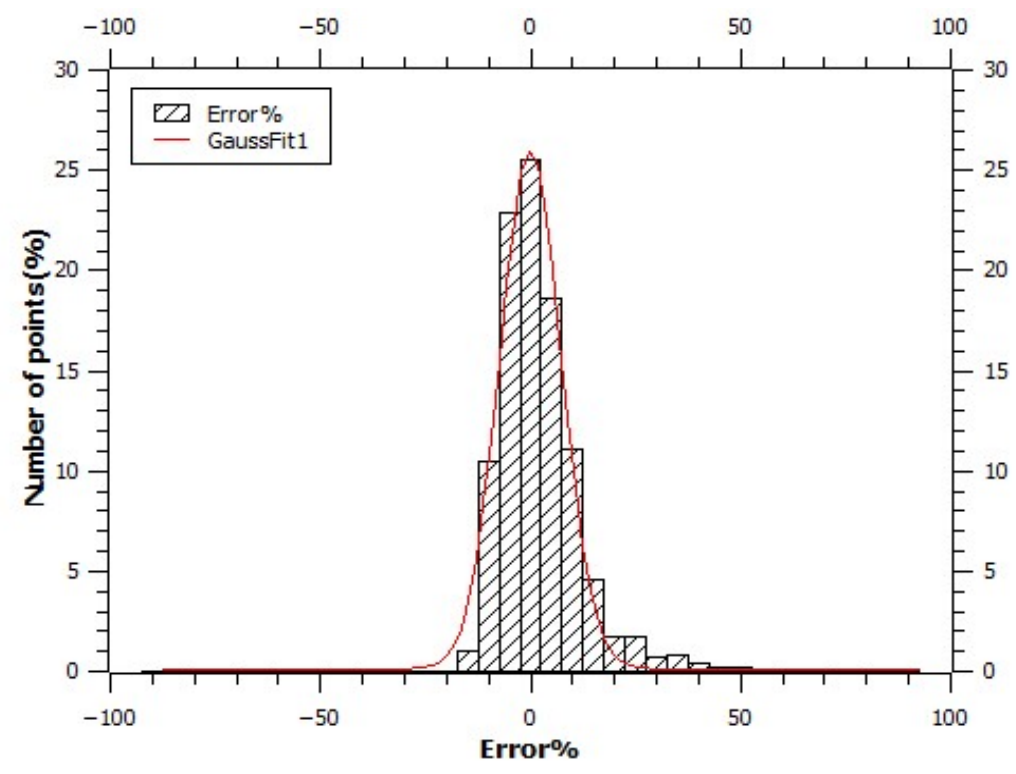

Source: Author 
DNBR data shown in Fig. 4 correspond to those runs for which calculated CHF subchannel exit steam qualities were less than 0.20. This upper quality is still above the maximum quality (about $0.1)$ expected to occur in typical PWR fuel elements under normal operation.

Figure 4: Ratio of Predicted CHF to Measured CHF for Local Steam Quality $<0.2$

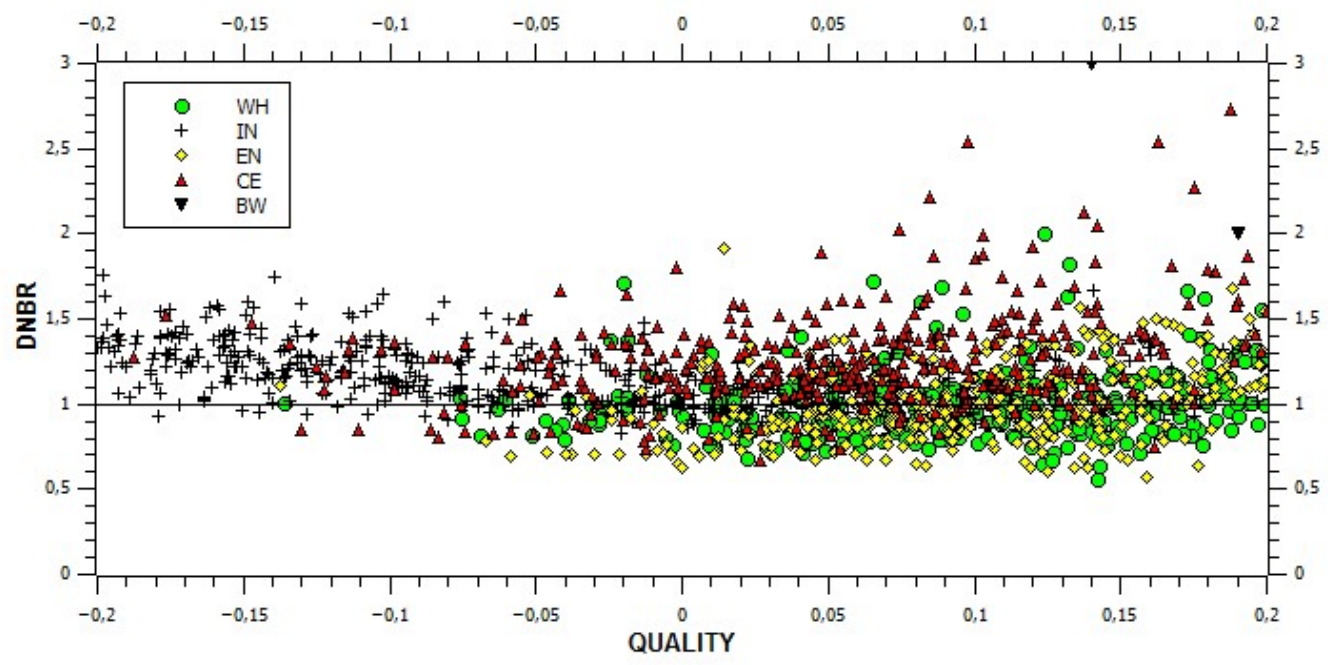

Source: Author

\section{CONCLUSIONS}

This work concerned the assessment of critical heat flux (CHF) measurements taken from $5 \times 5$ test sections simulating nuclear fuel assemblies of pressurized water reactors. The study, although being carried out for specific geometries, reveals that the standard CHF tables for tubes appears as an interesting alternative for the determination of critical heat flux in nuclear fuel elements. In contrast with empirical correlations or semi-analytical CHF models, these tables are easy to be used and cover wide range of parameters.

Considering that the hypothesis for critical heat flux is a function of flow parameters at the point where CHF occurs and can also be applied to complex geometries, slight corrections to the CHF tables are expected to be necessary to extend them to rod bundles. However, since the prediction of CHF in subchannel geometries is considerably more difficult than the prediction of CHF in tubes, further investigations in the light of experimental results need to be conducted to confirm the above 
assumption. The effects of fuel assembly characteristics on CHF such as mixing vane grid spacers, wetted and heated equivalent diameters, flow mixing, and radial and axial heat flux distributions need to be considered.

Comparisons between calculated and measures critical heat fluxes indicate that $68 \%$ of the data were predicted within the $\pm 15 \%$ error range.

\section{ACKNOWLEDGMENTS}

The authors are grateful to FAPEMIG, CNPq, CNEN and Capes for the support.

\section{REFERENCES}

1. KATTO, Y., “Critical Heat Flux”, Advances in Heat Transfer, vol. 17, Academic Press, Inc., New York, 1985.

2. TONG, L. S., Boiling Heat Transfer and Two-Phase Flow, John Wiley \& Sons, Inc., New York, 1967.

3. TODREAS, N.E., KAZIMI, M.S., Nuclear Systems: Thermal Hydraulic Fundamentals. Hemisphere Publishing Corporation. New York, 1990.

4. COLlier, J. G. \& THOME, J. R., Convective Boiling and Condensation, $3^{\text {rd }}$ ed., Oxford Uni versity Press Inc., New York, 1996.

5. TONG, L. S. \& WEISMAN, J., Thermal Analysis of Pressurized Water Reactor, $3^{\text {rd }}$ ed., American Nuclear Society, La Grange Park, IL, 1996.

6. DOROSCHUK, V. E., LEVITAN, L. L., LANTZMAN, F. P., "Investigation into Burnout in Uniformly Heated Tubes”, ASME Paper 75-WA/HT-22, 1975.

7. DOROSCHUK, V. E. ET AL., "Tabular Data for Calculating Burnout when Boiling Water in Uniformly Heat Round Tubes”, Thermal Engineering, vol. 23, no. 9, p. 77-79, 1976. 
8. GROENEVELD, D. C., CHENG, S. C., DOAN, T., "1986 AECL-UO Critical Heat Flux Lookup Table", Heat Thermal Engineering, vol. 7, nos. 1-2, p. 46-62, 1986.

9. KIRILLOV, P. L. ET AL., "New CHF Table for Water in Round Tubes, Proceedings of the Fifth International Topical Meeting on Reactor Thermal Hydraulics”, NURET-5, (Salt Lake City, Sept. 21-24, 1992), p. 511-518, American Nuclear Society, La Grange Park, IL, 1992.

10. GROENEVELD, D. C. ET AL., “The 1995 Look-up Table for Critical Heat Flux in Tubes", Nuclear Engineering and Design, vol. 163, p. 1-23, 1996.

11. GROENEVELD, D. C. ET AL., "The Effect of Fuel Subchannel Geometry on CHF, Proceed ings of the Fifth International Topical Meeting on Reactor Thermal Hydraulics", NURET-5, (Salt Lake City, Sept. 21-24, 1992), p. 683-690, American Nuclear Society, La Grange Park, IL, 1992.

12. VELOSO, M. A. F. Análise Termofluidodinâmica de Reatores Nucleares de Pesquisa Refrigera dos a Água em Regime de Convecção Natural, Tese Doutorado, Faculdade de Engenharia Química, Universidade Estadual de Campinas, Campinas, SP, 2004.

13. FIGUETTI, C.F., REDDY, D.G., "Parametric study of CHF data. Thechinal Report EPRI-NP2609”. Eletric Power Research Institute, Palo Alto, CA, vol. 3, parts 1 and 2.

14. ROWE, D. S., COBRA-IIIC: “A Digital Program for Steady State and Transient ThermalHydraulic Analysis of Rod Bundle Nuclear Fuel Elements", BNWL-1695, Pacific Northwest Laboratories, Richland, WA, 1973.

15. VELOSO, M. A., "Determination of Spacer Loss and Turbulent Mixing Coefficients for Angra1 Reload Fuel Assemblies, Proceedings of the 9th Brazilian Meeting on Reactor Physics and Thermal Hydraulics”.(Caxambu, MG, Brazil, Oct. 25-29, 1993), p. 302-306, Associação Brasileira de Energia Nuclear, Rio de Janeiro, RJ, 1993.

16. LEVY, S., "Forced Convection Subcooled Boiling - Prediction of Vapor Volumetric Fraction". Int. J. Heat Transfer, vol. 10, p. 951-965, 1967.

17. SMITH, S. L., "Void Fraction in Two-Phase Flow. A Correlation Based upon an Equal Velocity Head Model”, Proc. Inst. Mech. Engrs., vol. 184, no. 36, p. 647-664, 1969-70. 
18. REDDY, D. G.; FIGUETTI, C. F.; MERILO, M., "Evaluation of Two-Phase Pressure Drop Correlation for High Pressure Steam-Water System", ASME-JSME Thermal Engineering Joint Conference Proceedings (Honolulu, March 20-24, 1983), vol. 1, p. 251-259, The American Society of Mechanical Engineers, New York, NY, 1983. 